\title{
Stat3-siRNA induces Fas-mediated apoptosis in vitro and in vivo in breast cancer
}

\author{
SATEESH KUNIGAL ${ }^{1}$, SAJANI S. LAKKA ${ }^{1}$, PRASANNA KUMAR SODADASU ${ }^{1}$, \\ NORMAN ESTES ${ }^{2}$ and JASTI S. RAO ${ }^{1,3}$ \\ Departments of ${ }^{1}$ Cancer Biology and Pharmacology, ${ }^{2}$ Surgery, and ${ }^{3}$ Neurosurgery, University of Illinois \\ College of Medicine at Peoria, One Illini Drive, Peoria, IL 61605, USA \\ Received December 23, 2008; Accepted February 9, 2009
}

DOI: 10.3892/ijo_00000249

\begin{abstract}
Stat3, a member of the signal transducer and activator of transcription family, has the potential to mediate cell survival, growth and differentiation. Stat 3 is constitutively activated in numerous cancers, including $>50 \%$ of breast cancers. Previous studies demonstrated that constitutively activated Stat 3 plays an important role in breast cancer development and progression by promoting cell proliferation and inhibiting apoptosis. The present study was designed to investigate the potential use of RNA interference (RNAi) to block Stat 3 expression and activation, as well as the subsequent effect on human breast cancer cell growth. Our studies show that knockdown of STAT3 expression by siRNA reduced expression of Bcl-xL and survivin in MDA-MB-231 cells, and also led to Fas mediated intrinsic apoptotic pathway by activating caspases $-8,-9,-3$ and PARP1 cleavage. In nude mice, pRNAi-Stat3 significantly suppressed tumor growth compared with controls. It also suppressed Stat3 expression, and downregulated BcL-xL and upregulated Fas, Fas-L and cleaved caspase-3 expression within the tumor, which significantly induced apoptosis and led to tumor suppression. Thus, targeting Stat3 signaling using siRNA may serve as a novel therapeutic strategy for the treatment of breast cancers expressing constitutively activated Stat3.
\end{abstract}

Correspondence to: Dr J.S. Rao, Department of Cancer Biology and Pharmacology, University of Illinois College of Medicine at Peoria, One Illini Drive, Peoria, IL 61605, USA

E-mail: jsrao@uic.edu

Abbreviations: RNAi, RNA interference; siRNA, short interfering RNA; Stat3, signal and transducer of transcription 3; pRNAi-Stat3, plasmid for small interfering RNA (siRNA) specific for Stat3; pSTAT3C, plasmid for constitutively active form of Stat3; pSV, plasmid for scrambled vector; PBS, phosphate-buffered saline; FITC, fluorescein 5-isothiocyanate; H\&E, hematoxylin and eosin; GAPDH, glyceraldehyde-3-phosphate dehydrogenase; TUNEL terminal deoxynucleotidyl transferase biotin-dUTP nick endlabeling

Key words: Stat3, apoptosis, Fas/Fas-L

\section{Introduction}

The STAT (signal transducer and activator of transcription) family of proteins are transcription factors known for their role as integrators of cytokine and growth factor receptor signaling and are required for cell growth, differentiation, motility and survival (1-3). Among the seven members of the mammalian STAT family, Stat3 has been most strongly implicated in oncogenesis. Stat 3 is ubiquitously expressed in mammalian cells and activated by cytokines (e.g., IL-6 family members), growth factors (e.g., EGF, PDGF), and the plasminogen activator system $(4,5)$. Tyrosine phosphorylation is pivotal for STAT activation, which in turn, leads to dimerization and translocation into the nucleus. The translocated activated Stat 3 binds to the consensus promoter sequences of target genes and initiates their transcription $(6,7)$. This tyrosine phosphorylation is transient in normal, non-transformed cells. In contrast, it is constitutively activated in the majority of cancer cell lines and a large number of primary tumors (6).

The expression of a constitutively active form of Stat3 (STAT3C) transforms immortalized human breast epithelial cells mediated by active MMP-9 tumorigenesis, thereby demonstrating the sufficiency of this transcription factor in promoting cellular transformation (8). Stat3 is constitutively activated in $>50 \%$ of primary breast tumors and tumor-derived cell lines. Abundant evidence shows that constitutively activated Stat 3 is frequently found in breast cancer samples (9). Thus, the Stat3 signaling pathway may represent a new molecular target for novel therapeutic approaches for breast cancer.

Strategies that target Stat3 signaling have been proposed including tyrosine kinase inhibitors (e.g., tyrphostin AG490 and cucurbitacin I), antisense oligonucleotides, decoy oligonucleotides, and dominant negative Stat3 protein (10-15). A more recent study demonstrated that Stat3 knockdown by RNA interference (RNAi) induced apoptosis in human neuron tumor cells and prostate cancer cells $(16,17)$. Stat3 participates in oncogenesis through the upregulation of genes encoding apoptosis inhibitors (Bcl-xL, Bcl2 and survivin) (18). Inhibition of Stat 3 activity reduced the expression of survivin in primary effusion lymphoma-induced cell apoptosis (19). Proteins of the Bcl-2 family are important regulators of the decision between survival or death in response to an apoptotic 
stimulus (20). Many studies have repeatedly demonstrated that the inhibition of STAT results in growth inhibition and induction of apoptosis in tumor cells harboring constitutive activation of Stat3 $(21,22)$. One possible explanation for the increased sensitivity of transformed cells to apoptosis compared with normal cells is that tumor cells may have become irreversibly dependent on STAT signaling to sustain their survival. The observed dependence of certain tumors, but not normal cells, on constitutive STAT activation for survival offers the potential for preferential tumor cell killing, and therefore, STAT inhibition has broad implications for cancer therapy.

Small interfering RNA (siRNA) are short double-stranded RNA molecules that can target complementary mRNA for degradation via a cellular process termed RNA interference (RNAi). RNAi is usually accomplished by introducing long double-stranded RNA molecules into cells. These RNA molecules are then cleaved into 21-nt to 23-nt RNA (known as siRNA) by an endonuclease (Dicer) in animal cells. The siRNA molecules then serve as a guide for sequence-specific degradation of homologous mRNA (23). The present study was designed to investigate the potential use of siRNA to block Stat 3 expression and the subsequent effect on growth of human breast cancer cells. We identified siRNA specific for Stat 3 and expressed the siRNA in breast cancer cells. Our results demonstrate that siRNA-mediated downregulation of Stat 3 expression inhibits the growth of human breast cancer cells and induces apoptotic cell death. These results demonstrate that targeting Stat 3 signaling using the siRNA technique may serve as a novel therapeutic strategy for the treatment of breast cancers expressing constitutively activated Stat3.

\section{Materials and methods}

Construction of plasmids that contain DNA templates for the synthesis of siRNAs were constructed under the control of the CMV promoter. pDNR-CMV (Clontech Laboratories, Inc., CA, USA) was used for DNA vector-based siRNA synthesis under the control of CMV promoter in vivo. In brief, first, the double-stranded DNA template encoding siRNA oligonucleotides (GeneBank access numbers for the human Stat3: NM003150) that contained a sense strand of 19 nucleotide sequences followed by a short space (TTCAAGAGA), the reverse complement of the sense strand, and five thymidines as an RNA polymerase III transcriptional stop signal were synthesized. The sequences were forward 5'-TCGAGTCAG GTTGCTGGTCAAATTCGAGTCGTCGGAATTTGACCA GCAACCTGACTTTTT-3' and reverse 5'-CTAGAAAAAG TCAGGTTGCTGGTCAAATTCCGACGACTCGAATTTG ACCAGCAACCTGAC-3' (located on SH2 domain). The oligonucleotides were annealed in a buffer (potassium actate 100 and $30 \mathrm{mmol} / 1$ HEPES-KOH pH 7.4, and magnesium acetate $2 \mathrm{mmol} / \mathrm{l}$ ) and the mixture was incubated at $90^{\circ} \mathrm{C}$ for $3 \mathrm{~min}$ and then at $37^{\circ} \mathrm{C}$ for $1 \mathrm{~h}$. The double stranded oligos were cloned into the ApaI-EcoR I sites of the pDNR-CMV vector (Ambion Inc) where short hairpin RNAs (shRNA) were expressed under the control of the CMV promoter.

Antibodies and reagents. Primary antibodies against Stat3, MMP-2, MMP-9, PARP-1, GAPDH, HRP/FITC/Texas Red conjugated secondary antibodies were obtained from Biomeda (Foster City, CA); anti-caspases -8, -3 and -9 were from Cell Signaling (Boston, MA); cleaved Bid, Bax, Bcl-xL, Fas-L, FADD and mouse IgG were from Santa Cruz Biotechnology (Santa Cruz, CA); and Fas and cytochrome c were from Calbiochem (San Diego, CA). BCA reagent (Pierce, Rockford, IL), ECL reagent (Amersham Pharmacia, Piscataway, NJ), DAPI nuclear staining mounting solution (Vector Laboratories, Burlingame, CA), DAB peroxidase substrate (Sigma, St. Louis, MO), TUNEL Detection kit (Roche Molecular Biochemicals Indianapolis, IN) and Annexin-V-FITC Apoptosis Detection Kit (BioVision Mountain View, CA) were used for this study. pStat3-C (constructs of constitutively activated Stat3) was purchased from Addgene Inc. (Cambridge, MA) (Addgene plasmid 8722).

Cell culture and treatments. MDA-MB-231 human breast cancer cells were purchased from the American Type Culture Collection (Manassas, VA) and cultured in DMEM supplemented with $10 \%$ FBS in a humidified $\mathrm{CO}_{2}$ incubator at $37^{\circ} \mathrm{C}$. MDA-MB-231 cells were serum-starved for $12-18 \mathrm{~h}$, transfected with a plasmid siRNA construct against STAT3 using FuGENE HD transfection reagent according to the manufacturer's protocol (Roche Diagnostics Corp., Indianapolis, IN), and incubated in humidified $\mathrm{CO}_{2}$ atmosphere at $37^{\circ} \mathrm{C}$ for 6-8 h. The necessary amount of culture medium was then added and cells were returned to the incubator for $36 \mathrm{~h}$ for few of the initial experiments and $48 \mathrm{~h}$ for remaining experiments. For blocking Fas-L on MDA-MB-231 cells, the serum-starved cells were treated with $10 \mu \mathrm{g} / \mathrm{ml}$ of anti-Fas-L antibody or non-specific IgG for $1 \mathrm{~h}$ prior to the treatment of pRNAi-Stat 3 treatment.

Cytosolic and mitochondrial protein extraction. Cytosolic and mitochondrial fractions were isolated from control, $\mathrm{pSV}$ and pRNAi-Stat3-treated cells as described elsewhere (24). Cross-contamination of cytosol and mitochondria was determined on the basis of the amount of activity of marker enzymes for cytosol [lactate dehydrogenase (LDH) and mitochondria (succinate dehydrogenase (SDH)]. Protein levels in the samples were determined with Bio-Rad protein assay kit and analyzed by immunoblot using anti-cytochrome c and anti-smac/DIABLO antibodies.

Western blot analysis. MDA-MB-231 cells were transfected with $\mathrm{pSV}$ or pRNAi-Stat 3 as described above. After incubation, the cells were washed with ice-cold PBS and lysed in RIPA buffer containing protease inhibitors. Whole cell extracts were subjected to SDS-PAGE and subsequently transferred to a polyvinylidene difluoride membrane (PVDF) (Bio-Rad, Hercules, CA). The membranes were blocked with $7 \%$ non-fat dry milk and probed with antibodies (anti-Stat3, pStat3). Appropriate antibody conjugated with horseradish peroxidase was used as the secondary antibody, and membranes were developed according to an enhanced chemiluminescence protocol according to manufacturer's instructions.

Immunocytochemical analysis. MDA-MB-231 cells were transfected with pSV or pRNAi-Stat3 as described above. After incubation, cells were fixed with $4 \%$ formaldehyde and 
incubated with $3 \%$ bovine serum albumin in PBS at room temperature for $1 \mathrm{~h}$ for blocking. After the coverslips were washed with PBS, anti-STAT3 mouse IgG (Santa Cruz Biotechnology) was added at a concentration of 1:200. The slides were incubated at $4^{\circ} \mathrm{C}$ overnight and washed 3 times with PBS to remove excess primary antibody. Cells were then incubated with anti-mouse Texas red conjugate or antimouse FITC conjugates $\operatorname{IgG}$ (1:500 dilution) for $1 \mathrm{~h}$ at room temperature. The slides were then washed 3 times and covered with glass coverslips using Vectashield HardSet mounting medium with DAPI (Vector Laboratories, Burlingame, CA). Cells were viewed under a fluorescent microscope.

Electromobility shift assay (EMSA) and Western blotting. Nuclear extracts were prepared from MDA-MB-231 cells transfected with pSV or pRNAi-Stat 3 as described above. Cells were detached with EDTA and resuspended in buffer A [10 mM HEPES (N-2-hydroxyethylenepiperazine- $N$ '-2ethanesulfonic acid), $\mathrm{pH} 7.9,1.5 \mathrm{mM} \mathrm{MgCl}_{2}, 10 \mathrm{mM} \mathrm{KCl}$, $0.5 \mathrm{mM}$ dithiothreitol (DTT)] containing protease inhibitors [1 mM phenylmethylsulfonyl fluoride (PMSF), $5 \mathrm{mM}$ iodoacetamide, $0.1 \mathrm{mM}$ quercetin, $10 \mu \mathrm{g} / \mathrm{ml}$ aprotinin, $10 \mu \mathrm{g} / \mathrm{ml}$ leupeptin, $0.3 \mathrm{mM}$ sodium vanadate] and incubated on ice for $15 \mathrm{~min}$. After homogenization using a Wheaton $0.1-\mathrm{ml}$ homogenizer, the nuclei were collected by centrifugation. The pellet was resuspended in buffer B (20 mM HEPES, pH 7.9, 25\% glycerol, $1.5 \mathrm{mM} \mathrm{MgCl} 2,420 \mathrm{mM} \mathrm{NaCl}, 0.2 \mathrm{mM}$ EDTA, $0.5 \mathrm{mM}$ DTT) containing protease inhibitors and was incubated on ice for $30 \mathrm{~min}$, followed by centrifugation at $13,000 \mathrm{~g}\left(5 \mathrm{~min}, 4^{\circ} \mathrm{C}\right)$. The supernatant was dialyzed against buffer C (20 mM HEPES, 20\% glycerol, $100 \mathrm{mM}$ $\mathrm{KCl}, 0.2 \mathrm{mM}$ EDTA, $0.5 \mathrm{mM}$ DTT) containing protease inhibitors for $2 \mathrm{~h}$ at $4^{\circ} \mathrm{C}$, followed by centrifugation at $13,000 \mathrm{~g}$ $\left(5 \mathrm{~min}\right.$ at $\left.4^{\circ} \mathrm{C}\right)$. The supernatant proteins were used immediately or aliquoted and stored at $-80^{\circ} \mathrm{C}$.

Binding reaction was performed for $30 \mathrm{~min}$ on ice in a volume of $20 \mu \mathrm{l}$, which contained $4 \mu \mathrm{g}$ nuclear protein extracts, $40 \mathrm{ng}$ poly $(\mathrm{dI}-\mathrm{dC}), 4 \mu 15 \mathrm{X}$ binding buffer ( $1 \mathrm{X}$ binding buffer: $20 \mathrm{mM}$ HEPES, $\mathrm{pH} 7.9,50 \mathrm{mM} \mathrm{KCl}, 5 \mathrm{mM}$ $\mathrm{MgCl}_{2}, 1 \mathrm{mM}$ EDTA, $1 \mathrm{mM}$ DTT, $10 \%$ glycerol) with or without 20- to 50-fold excess of cold competitor or of unrelated competitor and a $\left.{ }^{32} \mathrm{P}\right]$-labeled probe $\left(3 \times 10^{4} \mathrm{cpm}\right)$. For the supershift electrophoretic mobility shift assay (EMSA), protein extracts were incubated with $6 \mu \mathrm{g}$ STAT3 and HIF-1 $\alpha$ monoclonal antibody or non-specific IgG as control before the addition of the $\left[{ }^{32} \mathrm{P}\right]$-labeled probe. DNA-protein complexes were separated on $5 \%$ polyacrylamide gel in Tris/glycine buffer at $4^{\circ} \mathrm{C}$. The following double-stranded oligonucleotides purchased from Santa Cruz Biotechnology were used in this study: Stat 3 consensus oligonucleotide: sc-2571, 5'-GAT CC T TCT GGG AAT TCC TAG ATC-3'; 3'-CTA GGA AGA CCC TTA AGG ATC TAG-5'.

Five end-labeled probes were prepared with $40 \mu \mathrm{Ci}$ (1480 MBq) $\left[\gamma_{-}{ }^{32} \mathrm{P}\right]$-adenosine triphosphate (ATP) using T4 polynucleotide kinase. Probes were gel-purified on NAP-5 Sephadex G-25 DNA-grade columns.

Animal experiments. MDA-MB-231 cells were cultured in complete medium until $70-75 \%$ density was reached. Then, cells were trypsinized, washed once with serum-free medium and counted. Cells were injected bilaterally into the second mammary fat pads of athymic, female, 4-6-week-old nu/nu mice $\left(5 \times 10^{6} / 100 \mu 1\right.$ serum-free culture medium). Tumor growth was monitored daily. Once a tumor reached a size of $\sim 6-8 \mathrm{~mm}$, three doses of $150 \mu \mathrm{g}$ /animal of either pSV or pRNAi-Stat3 were given intraperitoneally on alternate days. One set of animals were sacrificed for tumors after 18 days of treatment while a second set of animals was kept under observation for a period of 6 weeks. Finally, the tumor volume was calculated using the formula: $V=\pi / 6$ ( $\mathrm{a} \times \mathrm{b} \times \mathrm{c})$.

Immunohistochemical analysis. Tumor samples fixed in 10\% neutral buffered formalin were embedded in paraffin using automatic embedding equipment. Five $\mu \mathrm{m}$ sections were prepared. Paraffin-embedded breast tumor sections of control mice and mice treated with pSV and pRNAi-Stat 3 were analyzed for Stat3, Fas and Fas-L using immunohistochemistry.

Apoptosis assay. Apoptosis was determined through the analysis of externalization of plasma membrane phosphatidylserine (PS) and TUNEL assay.

Annexin V-FITC apoptosis detection assay. An increase in the plasma membrane PS externalization occurs early in apoptosis and can be detected by annexin V staining. MDA-MB-231 cells were treated with pRNAi-Stat 3 as described above. After $96 \mathrm{~h}$, cells were isolated and stained with annexin V-FITC (BioVision Research Products, Mountain View, CA). Cells were analyzed using FACS for fluorescence of annexin Vpositive cells.

TUNEL assay. TUNEL assay was performed with paraformaldehyde-fixed, MDA-MB-231 cells as per the manufacturer's protocol (Roche Diagnostics Corp., Indianapolis, IN). Briefly, the TUNEL (Terminal deoxynucleotidyl Transferase Biotin-dUTP nick end-labeling) method identifies apoptotic cells in situ by using terminal deoxynucleotidyl transferase (TdT) to transfer biotin-dUTP to the free $3^{\prime}-\mathrm{OH}$ of cleaved DNA. The biotin-labeled cleavage sites are then visualized by reaction with fluorescein-conjugated avidin (avidin-FITC). The cells were visualized using a fluorescent microscope with appropriate filter sets. DNA fragmentation in these treated tumors is indicative of apoptotic cell population. Additionally, TUNEL assay was performed with paraformaldehyde-fixed, paraffin-embedded breast tumor sections.

Statistical analysis. Statistical comparisons were performed using analysis of variance for analysis of significance between different values using GraphPad Prism software (San Diego, $\mathrm{CA})$. Values are expressed as mean $\pm \mathrm{SE}$ from at least three separate experiments, and differences were considered significant at a $p<0.05$. Densitometric analysis was performed using ImageJ software (National Institutes of Health) was used to quantify the band intensities.

\section{Results}

pRNAi-Stat3 specifically reduces Stat 3 expression in MDA$M B-231$ cells. Since Stat3 levels are significantly higher in tumor cells (including breast tumor) than in normal cells, 


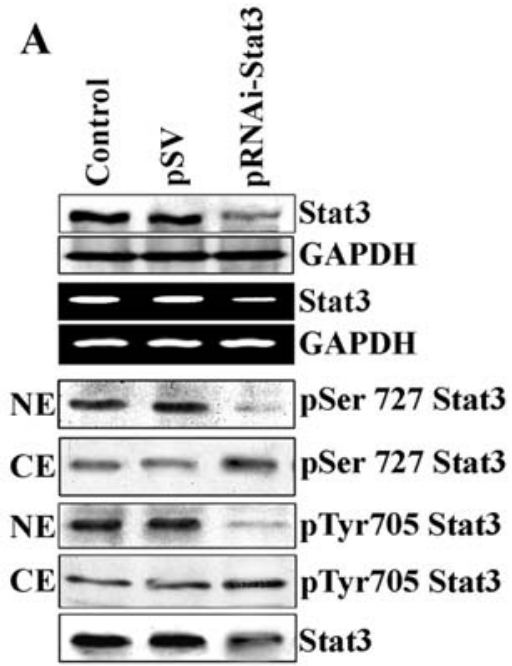

C
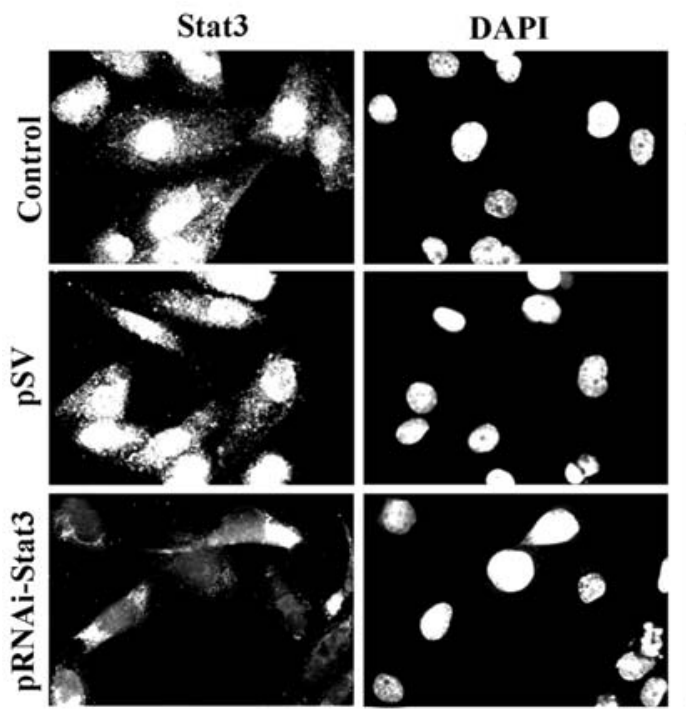

B

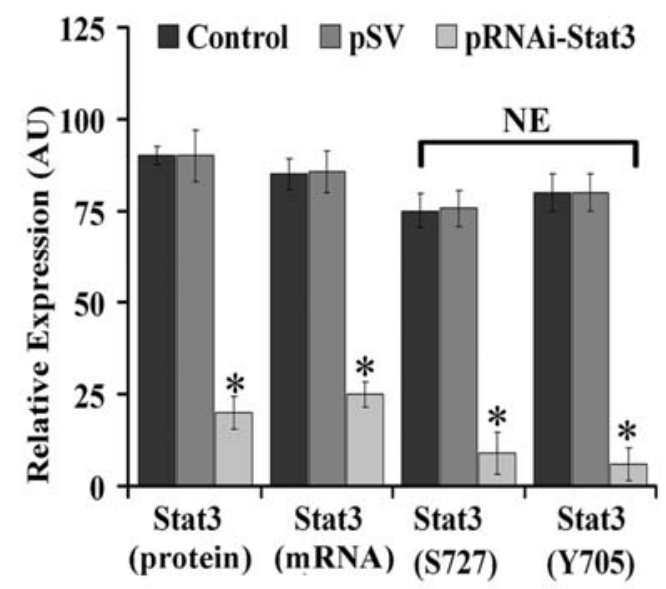

D

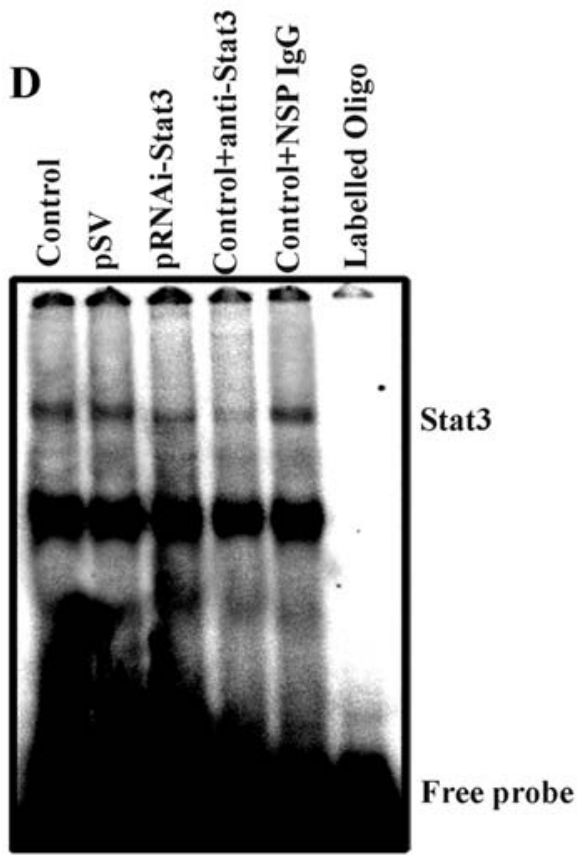

Figure 1. pRNAi-Stat3 specifically reduces Stat3 expression in MDA-MB-231 cells. Downregulation of Stat3 inhibits expression of Stat3 in MDA-MB-231 breast cancer cells. MDA-MB-231 cells were treated with pSV and pRNAi-Stat3. (A) Western blot analysis showing the effect of pRNAi-Stat3 on Stat3. Western blot analysis showing the effect of pRNAi-Stat3 on pSer727 and pTyr705-Stat3 from sub-cellular fractions. Anti-GAPDH antibody is used as a loading control. RT-PCR analysis to show the inhibition of expression of Stat3 at the mRNA level. Expression of GAPDH was verified for the equal loading of cDNA. (B) Densitometric analysis of the Western blot analysis. Bars represents the mean and SE of three experiments $\left({ }^{*} \mathrm{P}<0.05\right)(\mathrm{C})$ Immunocytochemical analysis of Stat3 in pRNAi-Stat3 in MDA-MB-231 cells. (D) Nuclear extracts were prepared and subjected to mobility shift assay to assess the DNA binding activity of Stat 3 and to check the specificity of the complex formed anti-Stat 3 antibody was used in the supershift assay (NE, nuclear ectract; CE, cytoplasmic extract).

we attempted to determine whether synthetic Stat3 siRNA could inhibit the expression of Stat 3 gene in MDA-MB-231 cells. Treatment of MDA-MB-231 cells with pRNAi-Stat3 (vector expressing siRNA for Stat3) for $36 \mathrm{~h}$ only resulted in a significant decrease of Stat 3 expression (by $>70 \%$ ) at both protein and mRNA levels compared to the untreated and the vector-treated MDA-MB-231 cells (Fig. 1A and B). Further, we analysed the phosphorylation status of Stat 3 in our pRNAi-Stat3-treated MDA-MB-231 cells using sub-cellular fractions. Fig. 1A and B showed that in pRNAi-Stat3-treated MDA-MB-231 cells, Stat3-ser-727 phosphorylation was significantly reduced (by $>75 \%$ ) in the nuclear extract (NE). Similarly, Stat3-Tyr-705 phosphorylation was significantly reduced (by $>85 \%$ ) in the nuclear extract (NE) in cells treated with pRNAi-Stat 3 indicating that pRNAi-Stat 3 also inhibited the activity of Stat3. In contrast, pTyr705 and pSer727-Stat3 (activated Stat3) was markedly expressed in the untreated and the vector-treated MDA-MB-231 cells (Fig. 1A and B), thereby supporting previous reports that Stat 3 is highly activated in the majority of cancer cell lines and in human cancers. So the Western blot analysis revealed that pRNAi-Stat3 inhibited the translocation of Stat3 into the nucleus in MDA-MB-231 cells. The immunocytochemical (ICC) analysis revealed the localization of the majority of Stat 3 in the nucleus of the control and vector-treated cells (Fig. 1C). In contrast, total expression including nuclear localization was reduced 

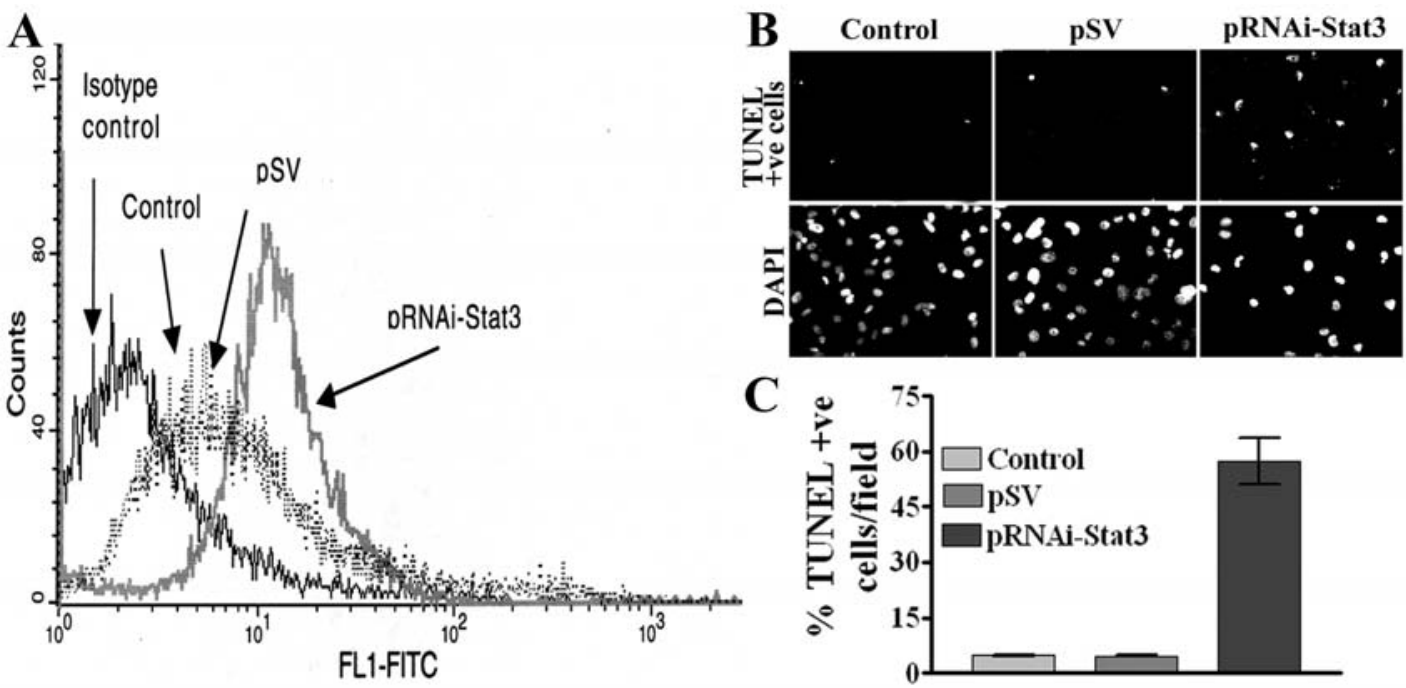

Figure 2. pRNAi-STAT3 induces apoptosis in breast cancer cells. Downregulation of Stat3 induces apoptosis in MDA-MB-231 breast cancer cells. MDA-MB-231 cells were treated for with pSV and pRNAi-Stat3. (A) FACS analysis for phosphatidylserine externalization using annexin-V-FITC staining. (B) Cells were stained for apoptosis by TdT-mediated dUTP nick end-labeling assay (TUNEL) staining. Data shown are from a representative experiment. (C) Quantitation of apoptotic cells indicated an increase in number of TUNEL-positive cells in pRNAi-Stat 3 treated cells. Bars represent the mean and SE of three experiments $\left({ }^{*} \mathrm{P}<0.05\right)$.

in the pRNAi-Stat3-treated cells. Furthermore, as shown by EMSA, treatment of MDA-MB-231 cells with pRNAi-STAT3 resulted in reduced DNA-binding activity of Stat3 as compared to the control and vector-treated cells (Fig. 1D). The specificity of the protein-DNA complex was demonstrated by a decrease in the intensity of the Stat 3 signal in the nuclear extracts from the control MDA-MB-231 cells treated with anti-Stat3 antibody (as reported by the manufacturer) in the supershift assay.

pRNAi-STAT3 induces apoptosis in breast cancer cells. In tumors Stat3 is known to regulate the expression of antiapoptotic genes and to transcriptionally regulate components of the apoptotic pathway (25). We analyzed the effect of treatment of MDA-MB-231 cells with pRNAi-Stat3 on apoptosis. We assessed apoptosis by looking for phosphatidylserine externalization using annexin- $\mathrm{V}$ binding and DNA fragmentation (TUNEL) assays. To quantify early and late events in the course of apoptosis, MDA-MB-231 cells were stained with annexin-V-FITC $36 \mathrm{~h}$ after pRNAi-Stat3 treatment. As shown by fluorescence-activated cell sorting analysis (Fig. 2A), transfection of MDA-MB-231 cells with pRNAi-Stat 3 induced annexin-V expression on the cell surface as compared to control and vector-treated cells. These results confirmed that the cells were undergoing apoptosis. Furthermore, the TUNEL assay results for cells at about $48 \mathrm{~h}$ post-transfection indicated a significant increase, nearly $70 \%$, in TUNEL-positive cells in pRNAi-Stat3-treated MDA-MB-231 cells as compared to the controls (Fig. 2B and C). In fact, very few TUNEL-positive cells were present in both the control and vector-treated cells. Taken together, these data indicate that Stat 3 plays a pivotal role as an antiapoptotic molecule in breast cancer and targeting Stat 3 activity led to the induction of apoptosis.

Inhibition of STAT3 expression downregulates survival genes and induces the activation of Fas/Fas-L and recruitment of
Fas-associated death domain (FADD) in MDA-MB-231 cells. The activation of Stat 3 has been shown to protect cancer cells from apoptotic stimuli emanating from the Fas (CD95/Apo-1) receptor or chemotherapeutic agents (26). This is accomplished as Stat 3 activation results in the transcriptional induction of the $\mathrm{Bcl}-\mathrm{x}$ gene promoter and high levels of the anti-apoptotic protein Bcl-xL. Thus, elevated levels of Stat3 appear to contribute directly to malignancy in multiple cancer cells by the prevention of apoptosis $(25,26)$. To determine whether these anti-apoptotic molecules are involved in the inhibition of apoptosis in MDA-MB-231 cells, we analyzed the expression of Bcl-xL/S. Using Western blotting, we found significant decreased expression of Bcl-xL $(\sim 70 \%)$ and increased expression of $\mathrm{Bcl}-\mathrm{xS}(\sim 50 \%)$, a proapoptotic molecule at the protein level (Fig. 3A and B) in MDA-MB-231 cells treated with pRNAi-Stat3. Also, the expression of survivin $(\sim 60 \%)$ was significantly reduced in MDA-MB-231 cells treated with pRNAi-Stat3 (Fig. 3A and B). This is noteworthy as survivin, a member of the IAP family, has recently been identified as a novel modulator of the cell death/viability balance in cancer (27). Thus, these data show that Stat 3 regulates the expression of anti-apoptotic genes in MDA-MB-231 cells.

We sought to further elucidate the molecular signaling involved in the apoptotic pathway. Cell membrane death receptor-induced apoptosis is widely studied in breast cancer, particularly in relation to hormonal disturbances (28). We investigated the involvement of death ligands including the Fas ligand (FasL). We found a significant increase in the expression of Fas $(\sim 60 \%)$ and Fas-L $(\sim 50 \%)$ in the pRNAiStat3-treated cells as compared to the untreated and vectortreated MDA-MB-231 cells (Fig. 3C and D). We also assessed the immediate downstream molecule in the death receptorinvolved apoptotic pathway. An early event in Fas activation of the apoptosis signaling cascade is the interaction or recruitment of FADD, the adaptor protein, following the 

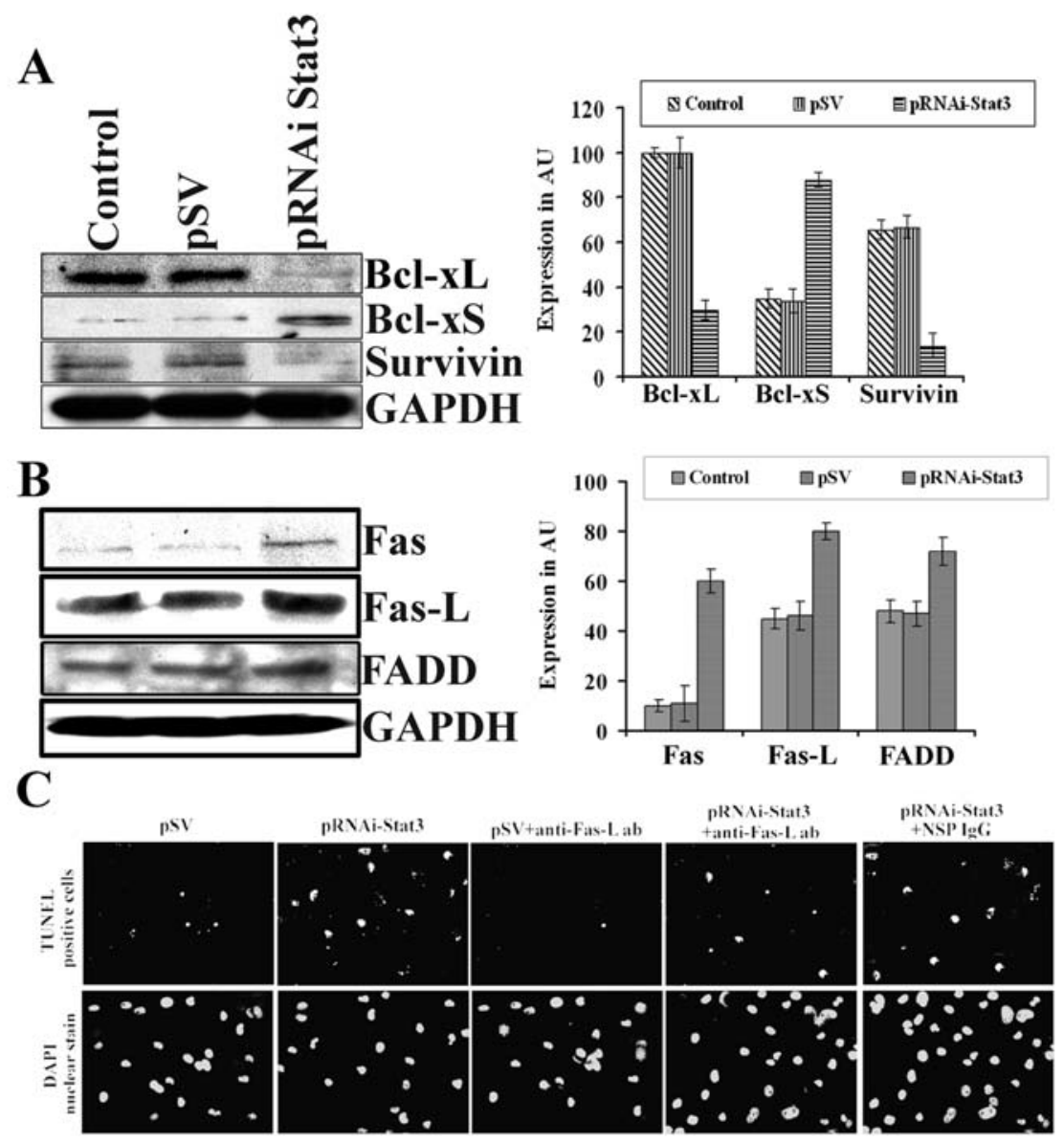

D

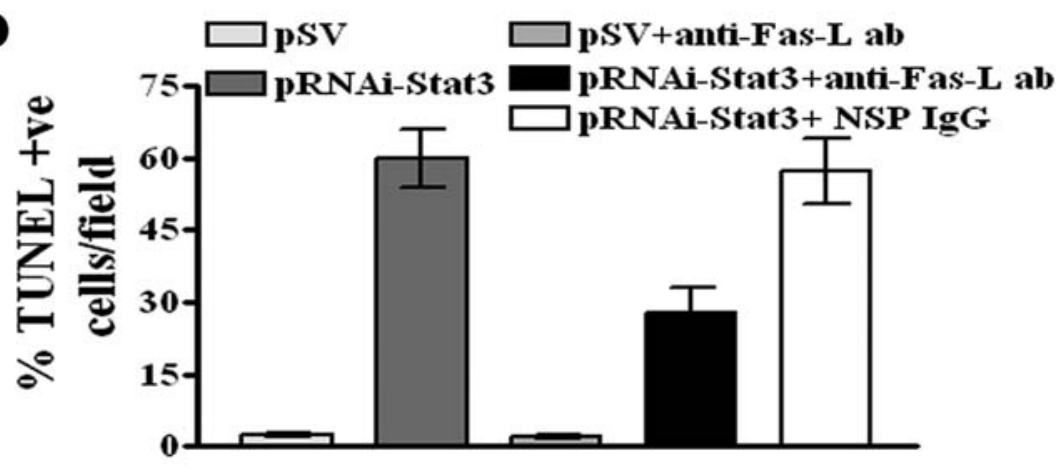

Figure 3. Inhibition of STAT3 expression downregulates survival genes and induces the activation of Fas/Fas-L and recruitment of Fas-associated death domain (FADD) in MDA-MB-231 cells. MDA-MB-231 cells were treated for with pSV and pRNAi-Stat3. (A) Cell lysates were used for immunoblot analysis of Bcl-xL, Bcl-xS and Survivin proteins. Densitometric analysis of the Western blot results. The bars indicate SE from the mean of three separate experiments $\left({ }^{*} \mathrm{P}<0.05\right)$. (B) Expression of the Fas receptor, Fas-L and FADD was measured by immunoblotting. GAPDH is used as a loading control. Densitometric analysis of the Western blot results. Results are a representative of 3 experiments. Antagonistic Fas-L antibodies block pRNAi-Stat3-induced apoptosis. MDA-MB-231 cells were incubated for $1 \mathrm{~h}$ with $10 \mathrm{~g} / \mathrm{ml}$ of antagonistic Fas-L antibody or nonspecific antibody before transfetion with pSV or pRNAi-Stat3 Forty-eight hours later, apoptosis was determined by: (C) TdT-mediated dUTP nick end-labeling assay (TUNEL) staining. Quantitation of TUNEL-positive cells. The bars indicate SE. from the mean of three separate experiments ( $\left.{ }^{*} \mathrm{P}<0.05\right)$. (D) Immunoblot analysis for cleavage of caspase- 8 and PARP. Apoptosis was not antagonized with non-specific antibody. Immunoblots are representative of three experiments.

interaction of Fas and Fas-L $(29,30)$. We found that pRNAiStat3-treated MDA-MB-231 cells showed a significant increase in FADD expression $(\sim 30 \%)$ as compared to the control and vector-treated MDA-MB-231 cells (Fig. 3C and D). To confer the role of Fas/Fas-L in apoptosis in Stat3 downregulated cells, we treated the MDA-MB-231 cells with Fas-L antibody prior to the pRNAi-Stat3 treatment. Fig. 3D shows pretreatment of MDA-MB-231 cells with Fas-L antibody followed by pRNAi-Stat 3 treatment reduced apoptotic cells by $>45 \%$ as determined by TUNEL staining.
Downregulation of Stat 3 alters pro- and anti-apoptotic gene expression and induces cleavage of PARP-1 and caspase-3, -8 and -9 . Some members of the $\mathrm{Bcl} 2$ family of proteins suppress apoptosis whereas other members promote apoptosis when activated by phosphorylation (unpublished data). An excess of Bax promotes cell death, but expression of Bcl2 can neutralize this effect (unpublished data). Fig. 4A shows that Bax expression increased in pRNAi-Stat3-treated MDAMB-231 cells as compared to the control and vector-treated cells. On the other hand, Bcl2 expression decreased in pRNAi- 


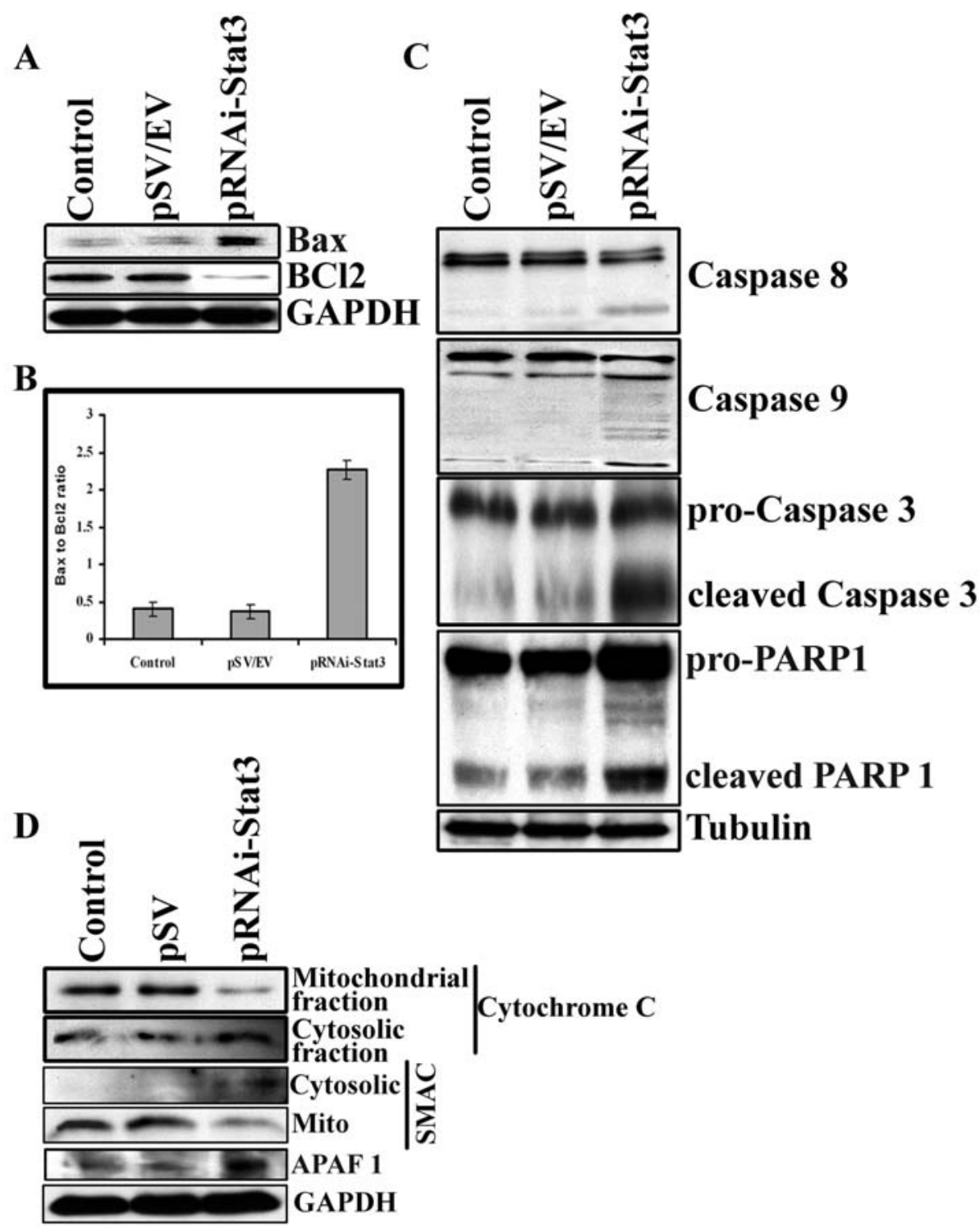

Figure 4. Downregulation of Stat3 alters pro- and anti-apoptotic gene expression and induces cleavage of PARP-1 and caspases -3, -8 and -9. (A) Cell lysates were used for immunoblot analysis of Bax and Bcl-2 proteins. (B) Densitometric analysis showing the Bax/Bcl2 ratio in treatment cells. The bars indicate SE from the mean of three separate experiments. (C) Processing of PARP and caspase-8, -9 and -3 was detected in total cell lysates. (D) Western analysis for SMAC/DIABLO, Cytochrome $\mathrm{c}$ release in the cytosol and APAF 1 in the cells treated with pRNAi-Stat3. Anti-GAPDH and anti-tubulin antibodies were used for visualizing equal protein loading. Immunoblots are representative of three experiments $\left({ }^{*} \mathrm{P}<0.05\right)$.

Stat3-treated MDA-MB-231 cells while Bcl2 expression was significantly higher in the control and vector-treated cells (Fig. 4A). The functional significance of these expression patterns derives from the potential for heterodimer formation between $\mathrm{Bax}$ and $\mathrm{Bcl} 2$. A high $\mathrm{Bax}: \mathrm{Bcl} 2$ ratio enhances the probability for Bax homodimer formation and cell death signaling, whereas a relative abundance of $\mathrm{Bcl} 2$ favors formation of $\mathrm{Bax} / \mathrm{Bcl} 2$ heterodimers and $\mathrm{Bcl} 2$ homodimers, which promote cell survival (unpublished data). Hence, we calculated the ratio of Bax expression to $\mathrm{Bcl} 2$ expression in the present study. The densitometric analysis showed a high Bax:Bcl2 ratio in the pRNAi-Stat3-treated MDA-MB-231 cells (Fig. 4B).

Since the high Bax: Bcl2 ratio enhances cell death signaling, we next determined whether members of the caspase family were activated. Treatment with pRNAi-Stat3 resulted in the cleavage of the effector caspase- 3 and the initiator caspases -8 and -9 as compared to the control and vector treatments. Further, we found the cleavage of PARP1 in pRNAi-Stat3-treated MDA-MB-231 cells, in particular, the $85 \mathrm{kDa}$ cleaved fragment was significantly higher in these cells as compared to the control and vector-treated cells (Fig. 4C).

The cleavage of caspases is aided by the release of caspaseactivating factors, particularly cytochrome $\mathrm{c}$ and Smac/Diablo from the mitochondrial membrane into the cytosol (31). In the present study, we found an increased signal for cytochrome $\mathrm{c}$ and Smac in the cytosolic fraction of pRNAi-Stat3treated MDA-MB-231 cells (Fig. 4D). Once released into the cytosol, cytochrome c activates apoptotic protease-activating factor 1 (Apaf-1), which together with pro-caspase 9, forms an active $700-\mathrm{kDa}$ holoenzyme complex known as the 

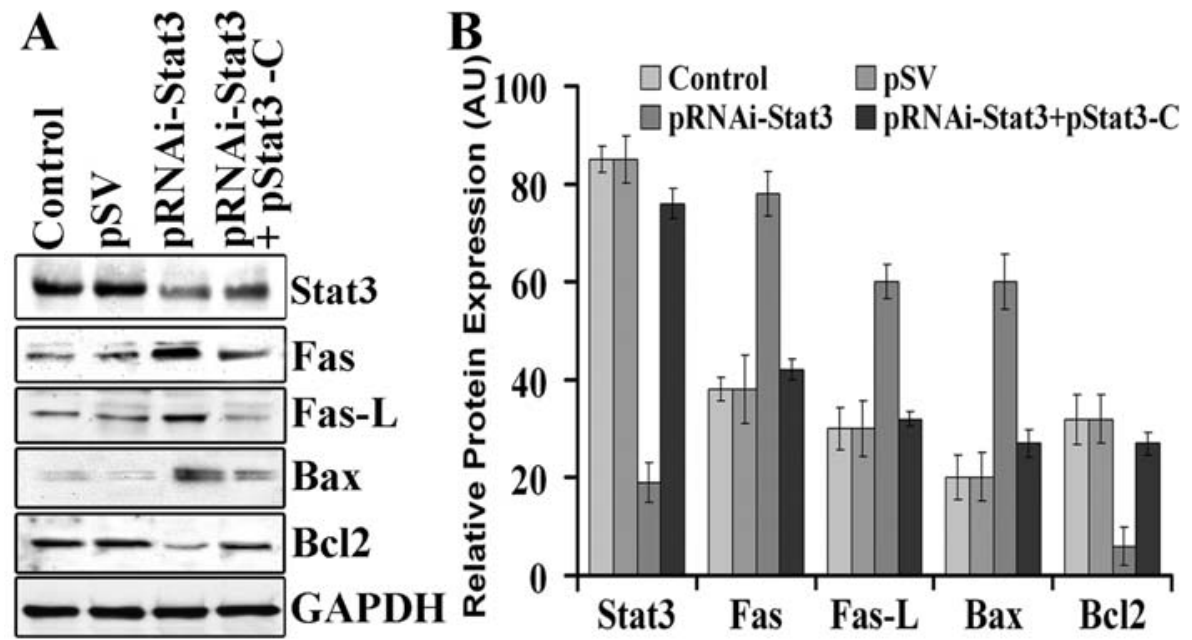

Figure 5. Constitutively activated Stat 3 plays a pivotal role in regulating the apoptosis in MDA-MB-231 cells. MDA-MB-231 cells were treated for with pSV, pRNAi-Stat3 and pRNAi-Stat3 + pStat3-C. (A) Cell lysates were used for immunoblot analysis of Fas, Fas-L, Bax and BcL-2 proteins. Anti-GAPDH antibody was used for visualizing equal protein loading. (B) Densitometric analysis of the Western blot results. Results are a representative of 3 separate experiments $\left({ }^{*} \mathrm{P}<0.05\right)$.

apoptosome (31). Fig. 4D shows significantly increased Apaf-1 expression in pRNAi-Stat3-treated MDA-MB-231 cells.

Constitutively activated Stat3 plays a pivotal role in regulating the apoptosis in MDA-MB-231 cells. Groner and Hennighausen (26), have shown that Stat 3 protects the cancer cells by regulating the expression of Fas. To show that Stat 3 plays an important role in regulating the apoptotic cascade in MDA-MB-231 cells, we used the constructs for constitutively activated Stat3 (pStat3-C). To accomplish this, we co-transfected MDA-MB-231 cells with pRNAi-Stat3 and pStat3-C. Fig. 5 shows the expression of Stat 3 is similar to that of control cells in pRNAi-Stat3-treated MDA-MB-231 cells when co-transfected with pStat3-C. Western blot analysis revealed reduced expression of Fas, Fas-L (by $>45 \%$ ), and Bax (by $>50 \%$ ) in the co-transfected cells when compared to the pRNAi-Stat 3 transfected cells. Additionally, the expression of $\mathrm{Bcl} 2$ drastically increased (reduced only by $10 \%$ ) in the co-transfected cells almost equaling the expression the pRNAiStat3-treated cells. This represents the importance of activated Stat 3 in breast cancer cells in protecting the cells from getting apoptosed and aiding in the growth of the tumor.

pRNAi-Stat 3 regresses orthotopic breast tumors in nude mice. After 18 days, pRNAi-Stat3 treatment of orthotopic breast tumors reduced tumor size by $>60 \%$ as compared to the control and vector treatments. Notably, we observed complete tumor regression after 6 weeks of treatment (Fig. 6A). We next determined whether the regression was a result of the induction of apoptosis. To show the efficacy of pRNAi-Stat3 treatment, we used the tumors harvested 18 days after treatment. The tumor tissue was fixed in $10 \%$ phosphate-buffered formaldehyde and sectioned. The tumor sections were stained with H\&E. Quantification of H\&E-stained breast tumor sections by a pathologist (blind review) revealed no difference between the control and empty vector-treated groups, as well as the presence of a high number of mitotic cells and more aggressive tumor characteristics. However, in the case of pRNAi-Stat3-treated tumor sections nearly a 3-fold increase in apoptotic cells was revealed (Fig. 6B). TUNEL assay of the tissue sections showed that few TUNEL-positive cells were present in the control and vector-treated tumors. In contrast, more than 4-fold more TUNEL-positive cells were present in the pRNAi-Stat3-treated tumors (Fig. 6B). Western blot analysis revealed that pRNAi-Stat3-treated tumors showed decreased Stat 3 expression, increased expression of Fas and Fas-L, increased signal for cleaved caspase-3 and decreased expression of Bcl-xL when compared to control and pSV-treated tumors (Fig. 6C). In addition, the immunohistochemical analysis of tumor tissue sections revealed increased expression of Fas and Fas-L and decreased expression of Stat3 in pRNAi-Stat3-treated tumors as compared to the control and vector-treated tumors (Fig. 6D).

\section{Discussion}

The evidence that activated Stat 3 has a pivotal role in breast tumorigenesis is based on studies of cell lines that express high levels of pStat3 (32). Knocking out Stat3 or blocking the phosphorylation of Stat3 leads to increased apoptosis, chemosensitivity, and decreased angiogenesis in both cell culture and xenograft models (33). Thus, inhibiting Stat3 activity or expression is likely to be an important therapeutic tool for a number of malignancies, including breast cancer.

RNAi represents a promising new technology that could have therapeutic applications for the treatment of diseases by blocking the action of transcription factors and oncogenes with selective silencing of gene expression with exquisite precision and high efficacy (34). In this study, we have identified the Stat3 siRNA that specifically inhibits constitutively activated Stat 3 and suppresses cell proliferation and induces apoptosis. One mechanism by which Stat 3 participates in tumorigenesis is by inhibiting apoptosis through the induction of anti-apoptotic genes. 
A

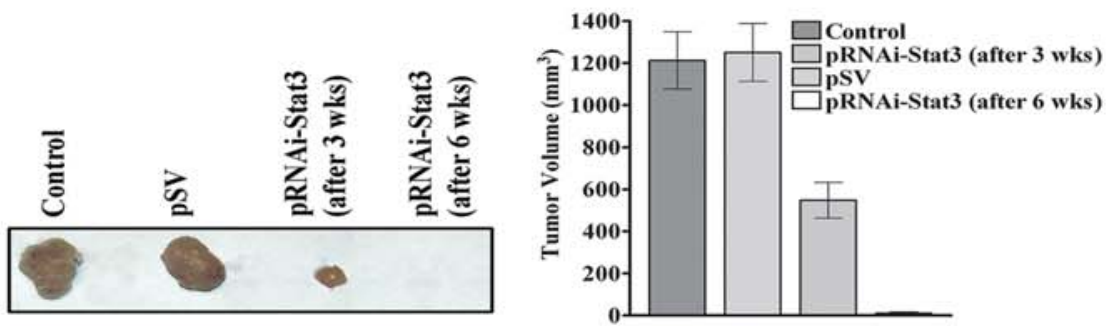

B

H \& E

TUNEL

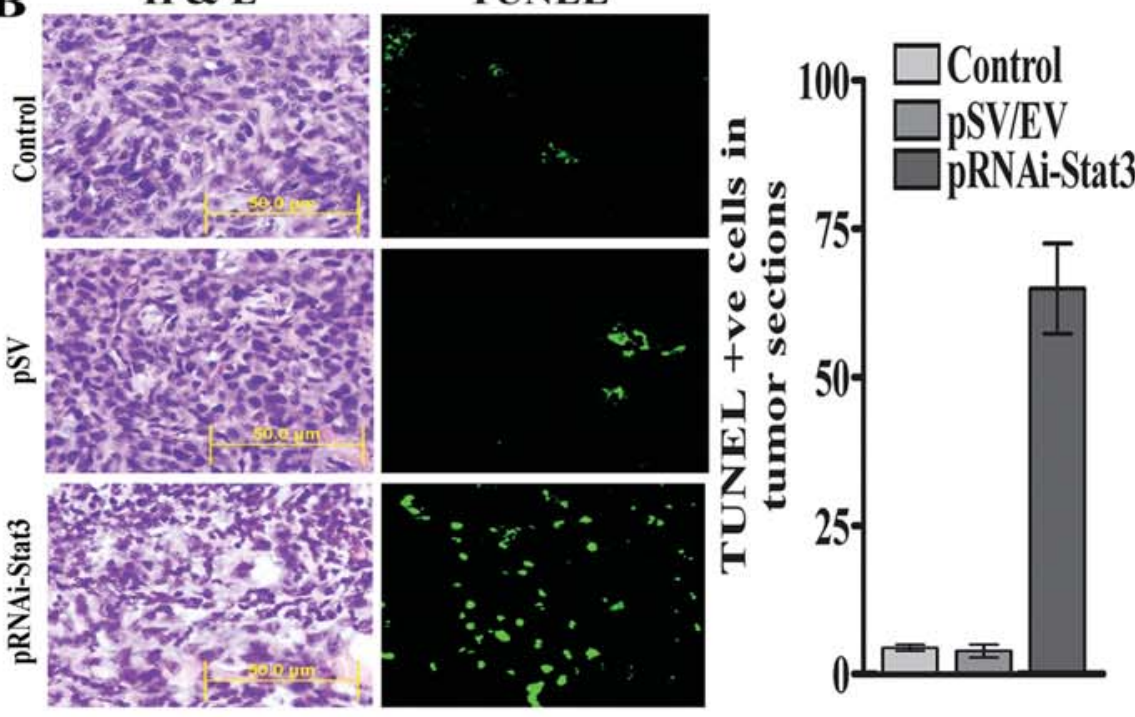

C
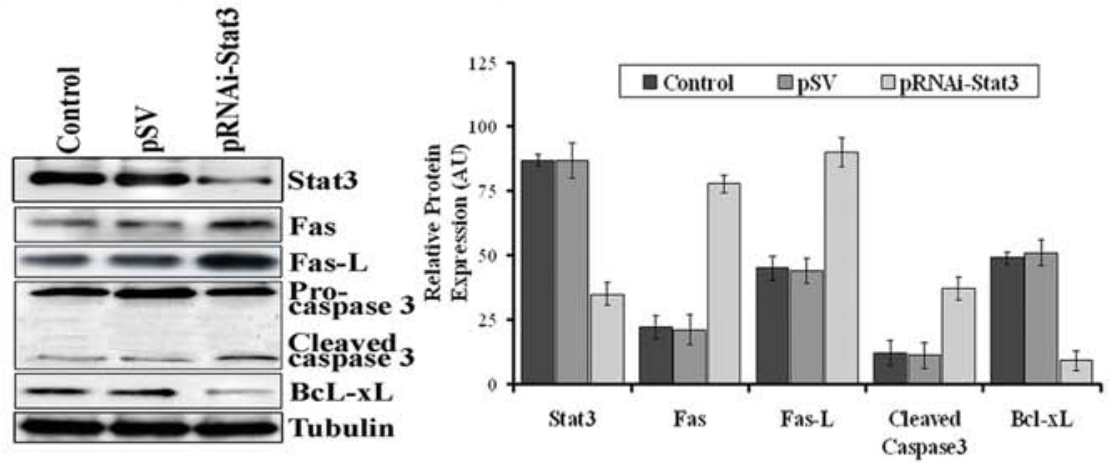

D

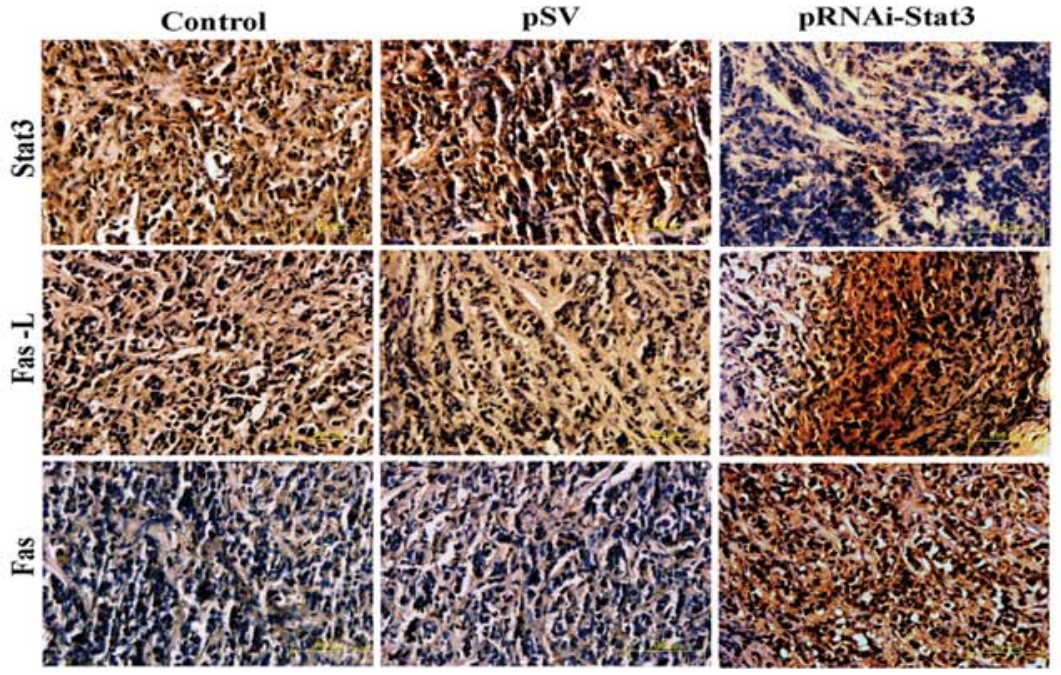

Figure 6. pRNAi-Stat3 regresses orthotopic breast tumors in nude mice. pRNAi-Stat3 treatment induces apoptosis in orthotopic breast tumors. (A) Tumor volume. (B) Tumor sections were subjected to H\&E staining and stained for apoptosis by TdT-mediated dUTP nick end-labeling assay (TUNEL) staining. Data shown are representative of 8 fields. Quantification of TUNEL ${ }^{+}$cells. The bars indicate SE from the mean of 8 microscopic fields. (C) Processing of Stat3, Fas, Fas-L, caspase-3 and BcL-xL was detected in tumor tissue lysates from the orthotopic breast tumors of mice, which received pSV and pRNAiStat3. Densitometric analysis of the Western blot results. Results are a representative of 3 separate experiments. (D) Immunohistochemical analysis Stat3, Fas and Fas-L was performed in paraffin-embedded breast tumor sections of mice treated with pSV and pRNAi-Stat3. 


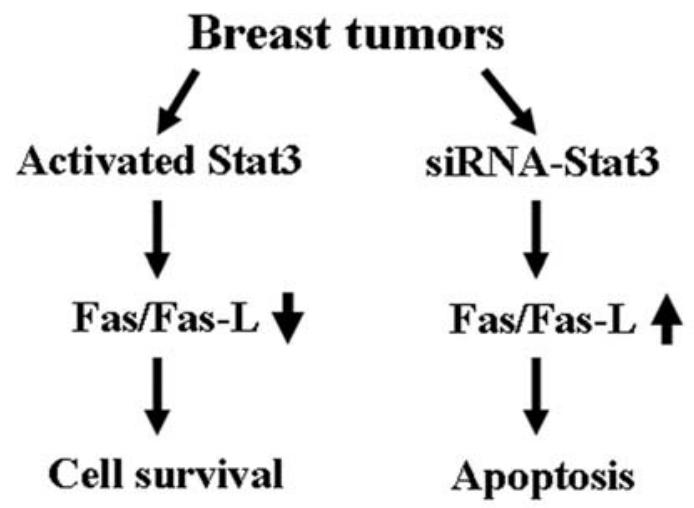

Figure 7. Schematic representation of the effect of pRNAi-Stat 3 on apoptotic cascade in breast tumor affecting growth.

The Fas/Fas ligand (Fas L) death pathway is an important mediator of apoptosis. Deregulation of the Fas pathway is reported to be involved in the immune escape of breast cancer and the resistance to anti-cancer drugs. Defects in the Fas/Fas $\mathrm{L}$ apoptotic signaling pathway provide a survival advantage to cancer cells and may be implicated in tumorigenesis (35). Significantly, constitutive downregulation of Fas is involved in drug resistance and associated with a poor prognosis in breast cancer. The expression of Fas is downregulated and the expression of Fas- $\mathrm{L}$ is upregulated in human breast invasive ductal carcinomas (36).

Numerous investigations have shown apoptosis is mediated by Fas/FasL system in cancer cells treated with anti-cancer agents $(37,38)$. Moreover, anti-cancer drugs are known to enhance FasL expression (39). FasL, which functions as an autocrine/paracrine mediator of apoptosis induced by DNA damaging anti-cancer chemotherapeutic agents, is a member of the TNF superfamily. It induces apoptosis in susceptible cells upon cross-linking to its own receptor, Fas (Apo-1/CD95). Once Fas interacts with Fas-L, it associates with the Fasassociated death domain (FADD) protein through the death domain-death domain interaction. Fas-bound FADD can physically associate with caspase- 8 . The interaction of caspase-8, an initiator caspase, with FADD results in the activation of caspase- 8 . This in turn leads to the activation of downstream caspases, including caspase-9 and -3 (40-42), as well as the translocation of Bax to mitochondria and translocation of cytochrome $\mathrm{c}$ and Smac/Diablo from the mitochondrial membrane to the cytosol (43-45). Finally, the activated caspases result in the cleavage of PARP-1 $(46,47)$. In the present study, Western blot analysis showed increased expression of Fas and Fas-L in pRNAi-Stat3-treated MDAMB-231 cells as compared to the control and vector-treated cells. Further, our results showed increases in the expression of Bax in the mitochondrial fraction, Smac/Diablo in the cytosolic fraction, and Apaf-1 in pRNAi-Stat3-treated MDAMB-231 cells as compared to the control and vector-treated cells.

Moreover, emerging evidence suggests that constitutive activation of Stat 3 appears to be ubiquitous in tumors where there is an imbalance in expression levels of anti-apoptotic and apoptotic genes that render tumor cells resistant to apoptosis $(17,48)$. Recent reports indicate Stat3 siRNA can induce apoptosis in astrocytomas and human prostate cancer $(16,49)$. The induction of apoptosis in all of these studies occurs via inhibition of the anti-apoptotic genes survivin and $\mathrm{Bcl}-\mathrm{xL}$ (a member of the Bcl-2 family of proteins), which play vital roles in cell survival $(16,17)$. Our results show that expression levels of the anti-apoptotic genes survivin and Bcl-xL were downregulated in pRNAi-Stat3-treated MDAMB-231 cells as compared to the control and vector-treated cells. Additionally, we found a significant increase in the expression of Bcl-xS in pRNAi-Stat3-treated MDA-MB-231 cells; Bcl-xS is a pro-apoptotic gene induced during apoptosis. The expression of Bcl-xS was negligible in the control and vector-treated cells. Our results strongly support that the constitutively activated Stat 3 protects the breast cancer cells from apoptosis.

We suggest a new strategy for treating breast cancer through downregulation of Stat3 using pRNAi-Stat3 (Fig. 7). The decreased Stat 3 activity of tumors increased the expression of Fas and Fas-L. Additionally, released the cytochrome $\mathrm{c}$ and SMAC into the cytoplasm from the mitochondria activating the intrinsic apoptotic pathway. This in turn led to increased apoptosis, thereby regressing the tumor. Our schematic is based on our in vitro and in vivo model data showing an increase in apoptosis and tumor reduction.

These results strongly suggest that simultaneous activation of extrinsic and intrinsic pathways is involved in the phenomenon of apoptotic induction. These events are associated with multiple perturbations in apoptotic regulatory proteins including the following: cleavage/degradation of caspase- 8 , $-9,-3$, and PARP; cytosolic depletion of Bax; and the release of the mitochondrial proteins Smac/Diablo and Apaf-1. As STAT3 signaling is important for the survival of a number of human tumors, Stat3 siRNA could become an effective therapeutic agent for Stat3-dependent tumors.

\section{Acknowledgements}

We thank Shellee Abraham for preparing the manuscript, and Diana Meister and Sushma Jasti for reviewing the manuscript. We thank Noorjehan Ali for technical assistance, and Professor J.E. Darnell Jr for providing constitutively activated Stat 3 construct (Stat3C). This research was supported by National Cancer Institute Grant CA 75557, CA 92393, CA 95058, CA 116708, N.I.N.D.S. NS47699, NS57529 and NS61835, and Caterpillar, Inc., OSF Saint Francis, Inc., Peoria, IL (to J.S.R.).

\section{References}

1. Clevenger CV: Roles and regulation of stat family transcription factors in human breast cancer. Am J Pathol 165: 1449-1460, 2004.

2. Takeda K and Akira S: STAT family of transcription factors in cytokine-mediated biological responses. Cytokine Growth Factor Rev 11: 199-207, 2000.

3. Yu H and Jove R: The STATs of cancer - new molecular targets come of age. Nat Rev Cancer 4: 97-105, 2004.

4. Shushakova N, Tkachuk N, Dangers M, Tkachuk S, Park JK, Hashimoto K, Haller H and Dumler I: Urokinase-induced activation of the gp130/Tyk2/Stat3 pathway mediates a proinflammatory effect in human mesangial cells via expression of the anaphylatoxin C5a receptor. J Cell Sci 118: 2743-2753, 2005. 
5. Zhong Z, Wen Z and Darnell JE Jr: Stat3: a STAT family member activated by tyrosine phosphorylation in response to epidermal growth factor and interleukin-6. Science 264: 95-98, 1994

6. Bromberg J: Stat proteins and oncogenesis. J Clin Invest 109: $1139-1142,2002$

7. Darnell JE Jr: STATs and gene regulation. Science 277: 1630-1635, 1997.

8. Dechow TN, Pedranzini L, Leitch A, Leslie K, Gerald WL, Linkov I and Bromberg JF: Requirement of matrix metalloproteinase- 9 for the transformation of human mammary epithelial cells by Stat3-C. Proc Natl Acad Sci USA 101: 10602-10607, 2004

9. Garcia R, Yu CL, Hudnall A, Catlett R, Nelson KL, Smithgall T, Fujita DJ, Ethier SP and Jove R: Constitutive activation of Stat3 in fibroblasts transformed by diverse oncoproteins and in breast carcinoma cells. Cell Growth Differ 8: 1267-1276, 1997.

10. Blaskovich MA, Sun J, Cantor A, Turkson J, Jove R and Sebti SM: Discovery of JSI-124 (cucurbitacin I), a selective Janus kinase/signal transducer and activator of transcription 3 signaling pathway inhibitor with potent antitumor activity against human and murine cancer cells in mice. Cancer Res 63 1270-1279, 2003.

11. Leong PL, Andrews GA, Johnson DE, Dyer KF, Xi S, Mai JC, Robbins PD, Gadiparthi S, Burke NA, Watkins SF and Grandis JR: Targeted inhibition of Stat3 with a decoy oligonucleotide abrogates head and neck cancer cell growth. Proc Natl Acad Sci USA 100: 4138-4143, 2003.

12. Meydan N, Grunberger T, Dadi H, Shahar M, Arpaia E, Lapidot Z, Leeder JS, Freedman M, Cohen A, Gazit A, Levitzki A and Roifman CM: Inhibition of acute lymphoblastic leukaemia by a Jak-2 inhibitor. Nature 379: 645-648, 1996

13. Mora LB, Buettner R, Seigne J, Diaz J, Ahmad N, Garcia R, Bowman T, Falcone R, Fairclough R, Cantor A, Muro-Cacho C, Livingston S, Karras J, Pow-Sang J and Jove R: Constitutive activation of Stat 3 in human prostate tumors and cell lines: direct inhibition of Stat 3 signaling induces apoptosis of prostate cancer cells. Cancer Res 62: 6659-6666, 2002.

14. Nakajima K, Yamanaka Y, Nakae K, Kojima H, Ichiba M, Kiuchi N, Kitaoka T, Fukada T, Hibi M and Hirano T: A central role for Stat 3 in IL-6-induced regulation of growth and differentiation in M1 leukemia cells. EMBO J 15: 3651-3658, 1996

15. Ni Z, Lou W, Leman ES and Gao AC: Inhibition of constitutively activated Stat3 signaling pathway suppresses growth of prostate cancer cells. Cancer Res 60: 1225-1228, 2000.

16. Konnikova L, Kotecki M, Kruger MM and Cochran BH: Knockdown of STAT3 expression by RNAi induces apoptosis in astrocytoma cells. BMC Cancer 3: 23-31, 2003.

17. Lee SO, Lou W, Qureshi KM, Mehraein-Ghomi F, Trump DL and Gao AC: RNA interference targeting Stat 3 inhibits growth and induces apoptosis of human prostate cancer cells. Prostate 60: 303-309, 2004

18. Buettner R, Mora LB and Jove R: Activated STAT signaling in human tumors provides novel molecular targets for therapeutic intervention. Clin Cancer Res 8: 945-954, 2002.

19. Aoki Y, Feldman GM and Tosato G: Inhibition of STAT3 signaling induces apoptosis and decreases survivin expression in primary effusion lymphoma. Blood 101: 1535-1542, 2003

20. Reed JC: Bcl-2 family proteins. Oncogene 17: 3225-3236, 1998

21. Bromberg J and Darnell JE Jr: The role of STATs in transcriptional control and their impact on cellular function. Oncogene 19: 2468-2473, 2000.

22. Catlett-Falcone R, Dalton WS and Jove R: STAT proteins as novel targets for cancer therapy. Signal transducer an activator of transcription. Curr Opin Oncol 11: 490-496, 1999.

23. Zamore PD, Tuschl T, Sharp PA and Bartel DP: RNAi: doublestranded RNA directs the ATP-dependent cleavage of mRNA at 21 to 23 nucleotide intervals. Cell 101: 25-33, 2000

24. Li N, Ragheb K, Lawler G, Sturgis J, Rajwa B, Melendez JA and Robinson JP: Mitochondrial complex I inhibitor rotenone induces apoptosis through enhancing mitochondrial reactive oxygen species production. J Biol Chem 278: 8516-8525, 2003.

25. Desrivieres S, Kunz C, Barash I, Vafaizadeh V, Borghouts C and Groner B: The biological functions of the versatile transcription factors STAT3 and STAT5 and new strategies for their targeted inhibition. J Mammary Gland Biol Neoplasia 11: $75-87,2006$
26. Groner B and Hennighausen L: Linear and cooperative signaling: roles for Stat proteins in the regulation of cell survival and apoptosis in the mammary epithelium. Breast Cancer Res 2: 149-153, 2000.

27. Ambrosini G, Adida C and Altieri DC: A novel anti-apoptosis gene, survivin, expressed in cancer and lymphoma. Nat Med 3: 917-921, 1997.

28. Song RX and Santen RJ: Apoptotic action of estrogen. Apoptosis 8: 55-60, 2003.

29. Chinnaiyan AM, O'Rourke K, Tewari M and Dixit VM: FADD, a novel death domain-containing protein, interacts with the death domain of Fas and initiates apoptosis. Cell 81: 505-512, 1995.

30. Schaub FJ, Liles WC, Ferri N, Sayson K, Seifert RA and Bowen-Pope DF: Fas and Fas-associated death domain protein regulate monocyte chemoattractant protein-1 expression by human smooth muscle cells through caspase- and calpaindependent release of interleukin-1alpha. Circ Res 93: 515-522, 2003.

31. Lademann U, Cain K, Gyrd-Hansen M, Brown D, Peters D and Jaattela M: Diarylurea compounds inhibit caspase activation by preventing the formation of the active 700-kilodalton apoptosome complex. Mol Cell Biol 23: 7829-7837, 2003.

32. Diaz N, Minton S, Cox C, Bowman T, Gritsko T, Garcia R, Eweis I, Wloch M, Livingston S, Seijo E, Cantor A, Lee JH, Beam CA, Sullivan D, Jove R and Muro-Cacho CA: Activation of stat3 in primary tumors from high-risk breast cancer patients is associated with elevated levels of activated SRC and survivin expression. Clin Cancer Res 12: 20-28, 2006.

33. Berishaj M, Gao SP, Ahmed S, Leslie K, Al-Ahmadie H, Gerald WL, Bornmann W and Bromberg JF: Stat3 is tyrosinephosphorylated through the interleukin-6/glycoprotein 130/Janus kinase pathway in breast cancer. Breast Cancer Res 9: R32, 2007.

34. Semizarov D, Frost L, Sarthy A, Kroeger P, Halbert DN and Fesik SW: Specificity of short interfering RNA determined through gene expression signatures. Proc Natl Acad Sci USA 100: 6347-6352, 2003.

35. Toillon RA, Descamps S, Adriaenssens E, Ricort JM, Bernard D, Boilly B and Le BX: Normal breast epithelial cells induce apoptosis of breast cancer cells via Fas signaling. Exp Cell Res 275: 31-43, 2002.

36. Xia C, Zhao H and Tang X: [The expressions of Fas and Fas-L in human breast invasive ductal carcinomas and their surrounding tissues]. Zhonghua Wai Ke Za Zhi 37: 648-650, 1999.

37. Friesen C, Fulda S and Debatin KM: Cytotoxic drugs and the CD95 pathway. Leukemia 13: 1854-1858, 1999.

38. Mo YY and Beck WT: DNA damage signals induction of fas ligand in tumor cells. Mol Pharmacol 55: 216-222, 1999.

39. Micheau O, Solary E, Hammann A, Martin F and MancheBoitrel MT: Sensitization of cancer cells treated with cytotoxic drugs to fas-mediated cytotoxicity. J Natl Cancer Inst 89: 783-789, 1997.

40. Boldin MP, Goncharov TM, Goltsev YV and Wallach D: Involvement of MACH, a novel MORT1/FADD-interacting protease, in Fas/APO-1- and TNF receptor-induced cell death. Cell 85: 803-815, 1996.

41. Cho SG and Choi EJ: Apoptotic signaling pathways: caspases and stress-activated protein kinases. J Biochem Mol Biol 35: 24-27, 2002

42. Hsu H, Shu HB, Pan MG and Goeddel DV: TRADD-TRAF2 and TRADD-FADD interactions define two distinct TNF receptor 1 signal transduction pathways. Cell 84: 299-308, 1996.

43. Jurgensmeier JM, Xie Z, Deveraux Q, Ellerby L, Bredesen D and Reed JC: Bax directly induces release of cytochrome $\mathrm{c}$ from isolated mitochondria. Proc Natl Acad Sci USA 95: 4997-5002, 1998.

44. Marzo I, Brenner C, Zamzami N, Jurgensmeier JM, Susin SA, Vieira HL, Prevost MC, Xie Z, Matsuyama S, Reed JC and Kroemer G: Bax and adenine nucleotide translocator cooperate in the mitochondrial control of apoptosis. Science 281: 2027-2031, 1998.

45. Narita M, Shimizu S, Ito T, Chittenden T, Lutz RJ, Matsuda H and Tsujimoto Y: Bax interacts with the permeability transition pore to induce permeability transition and cytochrome $\mathrm{c}$ release in isolated mitochondria. Proc Natl Acad Sci USA 95: 14681-14686, 1998. 
46. Nicholson DW, Ali A, Thornberry NA, Vaillancourt JP, Ding CK, Gallant M, Gareau Y, Griffin PR, Labelle M, Lazebnik YA, et al: Identification and inhibition of the ICE/CED-3 protease necessary for mammalian apoptosis. Nature 376: 37-43, 1995.

47. Tewari M, Quan LT, O'Rourke K, Desnoyers S, Zeng Z, Beidler DR, Poirier GG, Salvesen GS and Dixit VM: Yama/ CPP32 beta, a mammalian homolog of CED-3, is a CrmAinhibitable protease that cleaves the death substrate poly(ADPribose) polymerase. Cell 81: 801-809, 1995.
48. Scott SL, Higdon R, Beckett L, Shi XB, Vere White RW, Earle JD and Gumerlock PH: BCL2 antisense reduces prostate cancer cell survival following irradiation. Cancer Biother Radiopharm 17: 647-656, 2002.

49. Gao L, Zhang L, Hu J, Li F, Shao Y, Zhao D, Kalvakolanu DV, Kopecko DJ, Zhao X and Xu DQ: Down-regulation of signal transducer and activator of transcription 3 expression using vector-based small interfering RNAs suppresses growth of human prostate tumor in vivo. Clin Cancer Res 11: 6333-6341, 2005. 